\title{
Bone Morphogenetic Protein 6 Polymorphisms are Associated With Systemic Lupus Erythematosus Susceptibility in the Korean Population
}

\author{
Ji-su MO (D), Soo-cheon CHAE(D) \\ Department of Pathology, Wonkwang University, School of Medicine, Iksan, Chon-buk, South Korea
}

\begin{abstract}
Objectives: This study aims to investigate whether bone morphogenetic protein 6 (BMP6) single-nucleotide polymorphism (SNP) is associated with susceptibility to systematic lupus erythematosus (SLE).

Patients and methods: We analyzed the genotype and allele frequencies of BMP6 SNPs using genomic deoxyribonucleic acid (DNA) isolated from 119 SLE patients (9 males, 110 females; mean age 36.4 years; range 19 to 59 years) and 509 healthy controls (323 males, 186 females; mean age 42.1 years; range 19 to 61 years). Genomic DNA was extracted from peripheral blood leukocytes using a standard phenol-chloroform method or by using a genomic DNA extraction kit. Erythrocyte sedimentation rate, C-reactive protein, and antinuclear antibody levels of SLE patients were recorded.

Results: Our results showed that the genotype frequencies of rs17557 and rs9505273 for BMP6 in SLE patients significantly differed from those of the control group ( $p=0.01$ and $p=0.04$, respectively). The genotype frequencies of the rs 17557 and rs9505273 for BMP6 in female SLE patients were also significantly different from those in female healthy controls ( $p=0.04$ and $p=0.03$, respectively). We also revealed that the distribution of the main haplotypes of BMP6 SNPs in SLE patients was significantly different from their distribution in healthy controls.

Conclusion: These results suggested that SNPs in BMP6 might be associated with susceptibility to SLE and that haplotypes of BMP6 polymorphisms might represent useful genetic markers for SLE.

Keywords: Bone morphogenetic protein 6; haplotype; polymorphism; systematic lupus erythematosus.
\end{abstract}

Systematic lupus erythematosus (SLE) is a chronic inflammatory and complex autoimmune disease caused by a combination of multiple genetic, hormonal, and environmental factors. ${ }^{1,2}$ SLE is accompanied by the presence of multiple autoantibodies, including an antinuclear antibody (ANA). ${ }^{3}$ SLE is a rare non-organ-specific disorder that occurs in 10 to 50 individuals per $100,000 .{ }^{4}$ Additionally, SLE occurs more frequently in females, with a ratio of 9:1 between females and males. $^{5}$

Bone morphogenetic proteins (BMPs) are members of the transforming growth factor- beta superfamily and widely considered as crucial molecules involved in cell proliferation, differentiation, apoptosis, and migration in various tissues. ${ }^{6,7}$ BMP6 (also known as vegetal related growth factor or vegetal related growth factor 1 ), is detected in various types of cancers and cancer cell lines and associated with cancer-cell growth, migration, and drug resistance. ${ }^{8}$ Human BMP6 is located in chromosome region $6 \mathrm{p} 23$ to $6 \mathrm{p} 24$ and consists of seven exons (NM_001718.5; NP_001709.1). BMP6 is expressed in arthritic synovium of rheumatoid arthritis (RA) patients and strongly upregulated by proinflammatory

Received: September 22, 2017 Accepted: January 08, 2018 Published online: January 29, 2018

Correspondence: Soo-cheon Chae, MD. Wonkwang University, Department of Pathology, School of Medicine, lksan, 54538 Chon-buk, South Korea. Tel: +82-063-850-6770 e-mail:chaesc@wku.ac.kr 
cytokines. ${ }^{9}$ We previously identified several candidate genes, including gamma-aminobutyric acid receptor pi subunit (GABRP), epithelial stromal interaction 1 (EPSTI1), and BMP6, associated with SLE and RA in our pilot study using a customized $3 \mathrm{~K}$ single-nucleotide polymorphism (SNP) chip, which revealed that polymorphisms in GABRP and EPSTI1 might be associated with susceptibility to SLE, and that haplotypes of GABRP and EPSTI1 SNPs are useful genetic markers for SLE. ${ }^{10,11}$ Therefore, in this study, we aimed to investigate whether BMP6 SNP is associated with susceptibility to SLE.

\section{PATIENTS AND METHODS}

We obtained genomic deoxyribonucleic acid (DNA) samples from 119 SLE patients (9 males, 110 females; mean age 36.4 years; range 19 to 59 years) and 509 healthy controls (323 males, 186 females; mean age 42.1 years; range 19 to 61 years) between February 2009 and December 2011 at Chonnam University Hospital and Wonkang University Hospital, respectively. DNA samples were provided by the Biobank of Wonkwang University Hospital (Iksan, Korea), a member of the National Biobank of Korea and supported by the Ministry of Health and Welfare. The study protocol was approved by the Wonkwang University Hospital Ethics Committee (WKUH1155). A written informed consent was obtained from each participant. The study was conducted in accordance with the principles of the Declaration of Helsinki.

Genomic DNA was extracted from peripheral blood leukocytes using a standard phenolchloroform method or by using a genomic
DNA extraction kit (iNtRON Biotechnology, Seongnam, Korea) according to manufacturer instructions. SLE patients were recruited from the outpatient clinic at Chonnam National University Hospital (Gwangju, Korea). SLE was diagnosed according to the criteria of the American College of Rheumatology. ${ }^{5}$ Erythrocyte sedimentation rate (ESR), C-reactive protein (CRP), and ANA levels in SLE patients were determined in a routine laboratory at Chonnam National University Hospital. Controls were recruited from the general population and had received comprehensive medical testing at Wonkwang University Hospital. All study participants were Korean, and the healthy controls ethnically matched individuals in the SLE-patient group.

The assay reagents for rs 1107495 , rs 9505273 , rs17557, rs76699422, and rs1044104 in the BMP6 gene were designed by Applied Biosystems (Applied Biosystems, Foster City, CA, USA). Global minor-allele frequency were as follows: rs1107495, G=0.2670/1337 (1000 Genomes; http://www.internationalgenome.org) and $\mathrm{G}=0.1827 / 5319$ (Trans-Omics for Precision Medicine [TOPMED]; https://www.nhlbi. nih.gov/research/resources/nhlbi-precisionmedicine-initiative/topmed/); rs9505273, $\mathrm{C}=0.2638 / 1321 \quad(1000$ Genomes $)$ and $\mathrm{C}=0.29621 / 8624 \quad$ (TOPMED); rs 17557 , $\mathrm{G}=0.4024 / 2015 \quad(1000 \quad$ Genomes $)$, $\mathrm{G}=0.4419 / 12866$ (TOPMED), $\mathrm{C}=0.4824 / 6274$ (GO-ESP; http://evs.gs.washington.edu/ EVS $/$ ), and $\mathrm{C}=0.4637 / 56251 \quad(\mathrm{ExAC}$; http://exac.broadinstitute.org); and rs1044104, $\mathrm{G}=0.4411 / 2209$ (1000 Genomes) and $\mathrm{G}=0.3782 / 11012$ (TOPMED). The reagents consisted of a $40 \times$ mix of unlabeled polymerase chain reaction $(\mathrm{PCR})$ primers and TaqMan

Table 1. Primer sequences used for genotype analysis

\begin{tabular}{lllc}
\hline Applications & Primers & Primer sequence $\left(5^{\prime} \rightarrow 3^{\prime}\right)$ & Regions \\
\hline TaqMan analysis & BMP6-TF1 & CCTTTTAAATGATGGTAAAAGAGAA & rs 1107495 \\
& BMP6-TR1 & GCTTCAGATCGGGGTATTGGTCAGA & rs9505273 \\
& BMP6-TF2 & TGGAATGACTGATGTGTGCTTTGGGAGATA & rs17557 \\
& BMP6-TR2 & TCCTGGCTGCAGTGTGGAAGAGGCCTGAAA & rs76699422 \\
BMP6-TF3 & CATGGTGGCTTTCTTCAAAGTGAGTGAGGT & rs1044104 \\
& BMP6-TR3 & CACGTGCGCACCACCAGGTCAGCCTCCAGC & \\
& BMP6-TF4 & TCAGAAGAAGGCTGGCTGGAATTTGACATC & \\
& BMP6-TR4 & CGGCCACTAGCAATCTGTGGGTTGTGACTC & \\
& BMP6-TF5 & AGAACCGTTCTGGTAAAGAAGAGTGAGCA & \\
\end{tabular}


minor groove binder probes (Table 1) labeled with FAM (fluorescein) and VIC fluorescent dyes, respectively. ${ }^{12}$ The reaction in $10 \mu \mathrm{L}$ was optimized to work with $0.125 \mu \mathrm{L} 40 \times$ reagent, $5 \mu \mathrm{L} 2 \times$ TaqMan genotyping master mix (Applied Biosystems, Foster City, CA, USA), and $2 \mu \mathrm{L}(50 \mathrm{ng})$ of genomic DNA. The PCR conditions were as follows: one cycle at $95^{\circ} \mathrm{C}$ for 15 minutes, followed by 40 cycles at $95^{\circ} \mathrm{C}$ for 15 seconds and $60^{\circ} \mathrm{C}$ for 45 seconds. PCR was performed on an ABI Plus system, and samples were read and analyzed using the $\mathrm{ABI}$ Plus software (Applied Biosystems, Foster City, CA, USA).

\section{Statistical analysis}

Patients and healthy controls were compared using case-control association analysis. Chi square tests were employed to estimate the Hardy-Weinberg equilibrium (HWE). Pair-wise comparison of bi-allelic loci was employed for analyses of linkage disequilibrium. Haplotype frequencies of BMP6 for multiple loci were estimated using the expectation maximization algorithm with SNPAlyze software (Dynacom, Yokohama, Japan). Logistic regression analyses (SPSS v11.5; SPSS Inc., Chicago, IL, USA) were used to calculate the odds ratios (with 95\% confidence intervals). Analysis of variance was applied to define the ESR, as well as CRP and ANA levels, of each genotype from individual SLE patients. A $p$ value $<0.05$ was considered statistically significant.

\section{RESULTS}

The BMP6 gene was identified as a candidate gene associated with SLE in our previous pilot study using a customized 3K SNP chip. We selected five SNPs, including rs1107495, rs9505273, rs17557 (Val368Val), rs76699422 (Thr311Pro), and rs1044104, in human BMP6 for large-sample genotyping based on their locations. All genotype frequencies were in HWE (data not shown). A SNP, rs76699422, from the National Center for Biotechnology Information SNP database, was also genotypically analyzed; however, analysis of 204 samples revealed only an AA genotype (data not shown), indicating that rs76699422 might represent a very rare polymorphism or monomorphism in the Korean population. The genotype and allele frequencies of rs1107495 and rs1044104 were not significantly different

\begin{tabular}{|c|c|c|c|c|c|c|c|c|}
\hline \multirow[t]{2}{*}{ Position* } & \multirow[t]{2}{*}{ Genotype/Allele } & \multicolumn{2}{|c|}{ Healthy controls } & \multicolumn{2}{|c|}{ SLE patients } & \multirow{2}{*}{\multicolumn{2}{|c|}{ Odds ratio $+(95 \% \mathrm{CI})$}} & \multirow[b]{2}{*}{$p \neq$} \\
\hline & & $\mathrm{n}$ & $\%$ & $\mathrm{n}$ & $\%$ & & & \\
\hline \multirow[t]{5}{*}{ rs1107495 } & GG & 142 & 28.5 & 26 & 21.8 & 1.00 & & \multirow{3}{*}{0.09} \\
\hline & GA & 234 & 46.9 & 69 & 58.0 & 0.66 & $0.40-1.10$ & \\
\hline & AA & 123 & 24.6 & 24 & 20.2 & 1.61 & $0.98-2.65$ & \\
\hline & G & 518 & 51.9 & 121 & 50.8 & 1.00 & & \multirow{2}{*}{0.77} \\
\hline & A & 480 & 48.1 & 117 & 49.2 & 1.04 & $0.79-1.39$ & \\
\hline \multirow[t]{5}{*}{ rs9505273 } & $\mathrm{CC}$ & 171 & 33.6 & 52 & 44.1 & 1.00 & & \multirow{3}{*}{0.01} \\
\hline & $\mathrm{CT}$ & 246 & 48.3 & 57 & 48.3 & 0.42 & $0.20-0.89$ & \\
\hline & TT & 92 & 18.1 & 9 & 7.6 & 0.76 & $0.50-1.16$ & \\
\hline & $\mathrm{C}$ & 588 & 57.8 & 161 & 68.2 & 1.00 & & \multirow{2}{*}{0.003} \\
\hline & $\mathrm{T}$ & 430 & 42.2 & 75 & 31.8 & 0.64 & $0.47-0.86$ & \\
\hline \multirow[t]{5}{*}{ rs17557 } & $\mathrm{CC}$ & 302 & 59.9 & 59 & 49.6 & 1.00 & & \multirow{3}{*}{0.04} \\
\hline & CG & 171 & 33.9 & 55 & 46.2 & 1.65 & $1.09-2.49$ & \\
\hline & GG & 31 & 6.2 & 5 & 4.2 & 0.83 & $0.31-2.21$ & \\
\hline & C & 775 & 76.9 & 173 & 72.7 & 1.00 & & \multirow{2}{*}{0.18} \\
\hline & G & 233 & 23.1 & 65 & 27.3 & 1.25 & $0.91-1.72$ & \\
\hline \multirow[t]{5}{*}{ rs1044104 } & $\mathrm{CC}$ & 249 & 50.4 & 56 & 47.1 & 1.00 & & \multirow{3}{*}{0.80} \\
\hline & $\mathrm{CT}$ & 196 & 39.7 & 51 & 42.9 & 0.94 & $0.47-1.90$ & \\
\hline & TT & 49 & 9.9 & 12 & 10.1 & 1.16 & $0.76-1.77$ & \\
\hline & $\mathrm{C}$ & 694 & 70.2 & 163 & 68.5 & 1.00 & & \multirow{2}{*}{0.64} \\
\hline & $\mathrm{T}$ & 294 & 29.8 & 75 & 31.5 & 1.09 & $0.80-1.47$ & \\
\hline
\end{tabular}

SLE: Systematic lupus erythematosus; CI: Confidence interval; * Calculated from translation start site; † Logistic regression analyses were used for calculating odds ratio $(95 \%$ confidence interval); $\neq$ Value was determined by Fisher's exact test or Chi square tests from a $2 \times 2$ contingency table. 


\begin{tabular}{|c|c|c|c|c|c|c|c|c|}
\hline \multirow[t]{2}{*}{ Position* } & \multirow[t]{2}{*}{ Genotype/Allele } & \multicolumn{2}{|c|}{ Healthy controls } & \multicolumn{2}{|c|}{ SLE patients } & \multirow{2}{*}{\multicolumn{2}{|c|}{ Odds ratio† $(95 \% \mathrm{CI})$}} & \multirow[b]{2}{*}{$p \neq$} \\
\hline & & $\mathrm{n}$ & $\%$ & $\mathrm{n}$ & $\%$ & & & \\
\hline \multirow[t]{5}{*}{ rs1107495 } & GG & 48 & 27.0 & 24 & 21.8 & 1.0 & & \multirow{3}{*}{0.33} \\
\hline & GA & 94 & 52.8 & 62 & 56.4 & 1.32 & $0.73-2.37$ & \\
\hline & AA & 36 & 20.2 & 24 & 21.8 & 1.33 & $0.65-2.72$ & \\
\hline & G & 190 & 53.4 & 110 & 50.0 & 1.0 & & \multirow{2}{*}{0.43} \\
\hline & A & 166 & 46.6 & 110 & 50.0 & 1.15 & $0.82-1.60$ & \\
\hline \multirow[t]{5}{*}{ rs9505273 } & $\mathrm{CC}$ & 66 & 35.5 & 50 & 45.9 & 1.0 & & \multirow{3}{*}{0.01} \\
\hline & $\mathrm{CT}$ & 91 & 48.9 & 52 & 47.7 & 0.75 & $0.46-1.25$ & \\
\hline & TT & 29 & 15.6 & 7 & 6.4 & 0.32 & $0.13-0.79$ & \\
\hline & $\mathrm{C}$ & 223 & 59.9 & 152 & 69.7 & 1.0 & & \multirow{2}{*}{0.02} \\
\hline & $\mathrm{T}$ & 149 & 40.1 & 66 & 30.3 & 0.65 & $0.46-0.93$ & \\
\hline \multirow[t]{5}{*}{ rs17557 } & $\mathrm{CC}$ & 118 & 63.4 & 55 & 50.0 & 1.0 & & \multirow{3}{*}{0.008} \\
\hline & CG & 56 & 30.1 & 50 & 45.5 & 1.92 & $1.16-3.15$ & \\
\hline & GG & 12 & 6.5 & 5 & 4.5 & 0.89 & $0.30-2.66$ & \\
\hline & C & 292 & 78.5 & 160 & 72.7 & 1.0 & & \multirow{2}{*}{0.11} \\
\hline & G & 80 & 21.5 & 60 & 27.3 & 1.37 & $0.93-2.01$ & \\
\hline \multirow[t]{5}{*}{ rs1044104 } & $\mathrm{CC}$ & 96 & 52.2 & 52 & 47.3 & 1.0 & & \multirow{3}{*}{0.41} \\
\hline & $\mathrm{CT}$ & 72 & 39.1 & 47 & 42.7 & 1.21 & $0.73-1.99$ & \\
\hline & TT & 16 & 8.7 & 11 & 10.0 & 1.27 & $0.55-2.94$ & \\
\hline & $\mathrm{C}$ & 264 & 71.7 & 151 & 68.6 & 1.0 & & \multirow{2}{*}{0.42} \\
\hline & $\mathrm{T}$ & 104 & 28.3 & 69 & 31.4 & 1.16 & $0.81-1.67$ & \\
\hline
\end{tabular}

SLE: Systematic lupus erythematosus; CI: Confidence interval; ${ }^{*}$ Calculated from the translation start site; $\dagger$ Logistic regression analyses were used for calculating OR ( $95 \% \mathrm{CI}$; confidence interval); $\neq$ Value was determined by Fisher's exact test or Chi square tests from a $2 \times 2$ contingency table.

between SLE patients and healthy controls; however, the genotype frequencies of rs 9505273 $(p=0.01)$ and $r$ s17557 $(p=0.04)$ in SLE patients significantly differed from those in the control group (Table 2). The allele frequencies of BMP6 polymorphism rs9505273 in the SLE group were also significantly different from those in the control group ( $p=0.003$; Table 2). We further analyzed genotype and allele frequencies between female controls and female SLE patients, given that the SLE patients were predominantly female as compared with the population in control subjects. Although the genotype and allele frequencies of the rs1107495 and rs1044104 polymorphisms were not significantly different between female SLE patients and female controls, the genotype frequencies of the rs9505273 ( $\mathrm{p}=0.01)$ and rs17557 $(\mathrm{p}=0.008)$ polymorphisms in female SLE patients were statistically significantly different from those of female healthy controls (Table 3).

Table 4. Analyses of erythrocyte sedimentation rate, C-reactive protein, and antinuclear antibody levels among each genotype of bone morphogenetic protein 6 single-nucleotide polymorphisms in systematic lupus erythematosus patients

\begin{tabular}{|c|c|c|c|c|c|c|c|c|c|c|}
\hline \multirow[t]{2}{*}{ Position* } & \multirow{2}{*}{ Genotype } & \multicolumn{2}{|r|}{ ESR } & \multirow[b]{2}{*}{$p \dagger$} & \multicolumn{2}{|r|}{ CRP } & \multirow[b]{2}{*}{$p^{\dagger}$} & \multicolumn{2}{|r|}{ ANA } & \multirow[b]{2}{*}{$p^{\dagger}$} \\
\hline & & $\mathrm{n}$ & Mean \pm SD & & $\mathrm{n}$ & Mean \pm SD & & $\mathrm{n}$ & Mean \pm SD & \\
\hline rs1107495 & $\begin{array}{l}\text { GG } \\
\text { GA } \\
\text { AA }\end{array}$ & $\begin{array}{l}24 \\
63 \\
23\end{array}$ & $\begin{array}{l}30.3 \pm 24.7 \\
30.9 \pm 25.2 \\
26.9 \pm 20.3\end{array}$ & 0.80 & $\begin{array}{l}24 \\
63 \\
23\end{array}$ & $\begin{array}{l}0.5 \pm 0.4 \\
0.8 \pm 2.4 \\
0.4 \pm 0.2\end{array}$ & 0.66 & $\begin{array}{l}23 \\
60 \\
24\end{array}$ & $\begin{array}{l}198.3 \pm 148 \\
276.7 \pm 226 \\
238.4 \pm 106\end{array}$ & 1.48 \\
\hline rs9505273 & $\begin{array}{l}\text { CC } \\
\text { CT } \\
\text { TT }\end{array}$ & $\begin{array}{c}49 \\
51 \\
9\end{array}$ & $\begin{array}{l}35.7 \pm 27.6 \\
25.6 \pm 20.5 \\
21.8 \pm 15.0\end{array}$ & 0.06 & $\begin{array}{c}49 \\
51 \\
9\end{array}$ & $\begin{array}{l}0.5 \pm 0.5 \\
0.8 \pm 2.6 \\
0.3 \pm 0.1\end{array}$ & 0.68 & $\begin{array}{c}53 \\
49 \\
5\end{array}$ & $\begin{array}{l}289.1 \pm 238 \\
231.0 \pm 185 \\
304.0 \pm 215\end{array}$ & 1.03 \\
\hline rs17557 & $\begin{array}{l}\text { CC } \\
\text { CG } \\
\text { GG }\end{array}$ & $\begin{array}{c}53 \\
53 \\
4\end{array}$ & $\begin{array}{l}27.8 \pm 21.0 \\
32.5 \pm 27.2 \\
23.0 \pm 14.0\end{array}$ & 0.51 & $\begin{array}{c}53 \\
53 \\
4\end{array}$ & $\begin{array}{l}0.8 \pm 2.6 \\
0.5 \pm 0.5 \\
0.3 \pm 0.1\end{array}$ & 0.74 & $\begin{array}{c}49 \\
49 \\
9\end{array}$ & $\begin{array}{l}275.1 \pm 243 \\
253.9 \pm 191 \\
248.9 \pm 176\end{array}$ & 0.14 \\
\hline rs1044104 & $\begin{array}{l}\mathrm{CC} \\
\mathrm{CT} \\
\mathrm{TT}\end{array}$ & $\begin{array}{c}51 \\
50 \\
9\end{array}$ & $\begin{array}{l}30.2 \pm 24.8 \\
30.3 \pm 24.6 \\
25.9 \pm 16.1\end{array}$ & 0.87 & $\begin{array}{c}51 \\
50 \\
9\end{array}$ & $\begin{array}{l}0.4 \pm 0.2 \\
0.9 \pm 2.7 \\
0.5 \pm 0.3\end{array}$ & 0.42 & $\begin{array}{c}47 \\
50 \\
9\end{array}$ & $\begin{array}{l}261.3 \pm 191 \\
237.6 \pm 197 \\
408.9 \pm 359\end{array}$ & 2.49 \\
\hline
\end{tabular}

* Calculated from translation start site; ESR: Erythrocyte sedimentation rate; CRP: C-reactive protein; ANA: Antinuclear antibody; SD: Standard deviation; † Values were analyzed by analysis of variance. 


\begin{tabular}{|c|c|c|c|c|c|c|c|}
\hline \multicolumn{4}{|c|}{ Haplotype } & \multicolumn{2}{|c|}{ Frequency* } & \multirow[b]{2}{*}{ Chi-square } & \multirow[b]{2}{*}{$p \dagger$} \\
\hline rs1107495 & rs9505273 & rs17557 & rs1044104 & Control & $\overline{\mathrm{SLE}}$ & & \\
\hline A & $\mathrm{C}$ & $\mathrm{C}$ & C & 0.18 & 0.25 & 4.41 & 0.04 \\
\hline G & $\mathrm{C}$ & $\mathrm{C}$ & $\mathrm{C}$ & 0.17 & 0.13 & 1.86 & 0.17 \\
\hline G & $\mathrm{T}$ & $\mathrm{C}$ & $\mathrm{C}$ & 0.15 & 0.17 & 0.75 & 0.39 \\
\hline A & $\mathrm{T}$ & C & C & 0.13 & 0.07 & 6.47 & 0.01 \\
\hline G & C & G & $\mathrm{T}$ & 0.06 & 0.10 & 7.44 & 0.0064 \\
\hline A & C & G & $\mathrm{T}$ & 0.05 & 0.07 & 1.90 & 0.17 \\
\hline G & C & C & $\mathrm{T}$ & 0.05 & 0.01 & 7.39 & 0.0066 \\
\hline G & $\mathrm{T}$ & G & $\mathrm{T}$ & 0.04 & 0.01 & 5.61 & 0.02 \\
\hline A & $\mathrm{T}$ & G & $\mathrm{T}$ & 0.03 & 0.02 & 1.74 & 0.19 \\
\hline G & $\mathrm{T}$ & $\mathrm{C}$ & $\mathrm{T}$ & 0.03 & 0.05 & 2.59 & 0.11 \\
\hline \multirow[t]{2}{*}{ A } & $\mathrm{C}$ & $\mathrm{C}$ & $\mathrm{T}$ & 0.02 & 0.05 & 10.78 & 0.001 \\
\hline & Oth & & & 0.14 & 0.07 & - & - \\
\hline
\end{tabular}

To determine any possible correlations between BMP6 polymorphisms and the clinical features of SLE, we investigated relationships between BMP6 SNPs and total serum ESR, CRP, and ANA levels in SLE patients (Table 4). We found that the SNPs identified in the SLE patients showed no significant associations with the ESR, CRP, or ANA levels (Table 4).

We estimated the haplotype frequencies of the BMP6 SNPs (rs1107495, rs9505273, rs17557, and rs1044104) between controls and SLE patients (Table 5). Of 16 possible haplotypes, seven and eight were identified as the main haplotypes $(>5 \%)$ in controls and SLE patients, respectively (Table 5), with the distribution of the major haplotype (ACCC) significantly different in SLE patients as compared with that in the controls $(p=0.04)$. The distribution frequency of the GCGT and GCCT haplotypes in SLE patients was highly different than that in controls $(p=0.0064$ and $p=0.0066$, respectively). These results suggested that the BMP6 polymorphisms might represent important genetic markers associated with SLE susceptibility.

\section{DISCUSSION}

Systematic lupus erythematosus is a chronic inflammatory disease characterized by the presence of autoantibodies against nuclear autoantigens, as well as cytoplasmic and circulating proteins. ${ }^{13}$ The disease is caused by a combination of environmental factors and multiple genetic factors. The major histocompatibility complex was the first genetic region reported as being associated with SLE, ${ }^{14}$ and since then, multiple genes have been identified as associated with SLE susceptibility. However, a recent estimate advocates that most of the genetic variations identified thus far only explain $~ 8 \%$ of genetic SLE risk. ${ }^{15}$ Over the previous decade, accumulating results from genome-wide association studies significantly expanded the list of SLE-susceptibility loci; however, the functional genetics related to SLE-associated SNPs largely remain undefined. SNPs in the signal transducer and activator of transcription 4 gene are associated with nephritis, as well as double stranded DNA autoantibodies in SLE patients, ${ }^{16}$ with accumulating reports also signifying that these SNPs are associated with clinical features of SLE. ${ }^{17-19}$ We previously reported that $\mathrm{rs} 1044856$ and $\mathrm{rs} 1359184$ in EPSTI1 are associated with elevated ESR and ANA levels in SLE patients, respectively, ${ }^{11}$ and also that SNPs in the Forkhead-box J1, ${ }^{20}$ interleukin coactosin-like $1,{ }^{21}$ thymic stromal lymphopoietin receptor, ${ }^{22}$ GABRP, ${ }^{10}$ and EPSTI1 genes ${ }^{11}$ are associated with SLE susceptibility in the Korean population. In the present study, we evaluated the association between BMP6 polymorphisms and SLE susceptibility.

Bone morphogenetic protein 6 plays critical roles in skeletal development, bone formation, and differentiation of stem cells, such as mesenchymal stem cells. ${ }^{23}$ The majority of BMP6-related 
research has focused on the development and differentiation of osteoblasts and various stem cells; therefore, the primary genetic association and function of BMP6 in SLE remain unknown. We previously identified several candidate genes, including BMP6, associated with SLE. ${ }^{10}$ In the present study, we analyzed the genotypes of the rs1107495, rs9505273, rs17557, rs76699422, and rs1044104 polymorphisms of BMP6 in SLE patients and healthy controls, finding that rs17557 and rs76699422 represented a synonymous SNP (Val368Val) and a missense SNP (Thr311Pro), respectively. However, our results indicated that rs76699422 was a very rare polymorphism or monomorphism in the Korean population. Furthermore, the genotype frequencies of rs17557 and rs9505273 in SLE patients were significantly different from those of the control group (Table 2), suggesting that these BMP6 polymorphisms might be associated with SLE susceptibility. Generally, synonymous variations affect messenger ribonucleic acid stability, secondary structure, and receptor synthesis and may result in potentially important pathophysiological alterations. ${ }^{24,25}$ The results presented here advocated that rs17557 in BMP6 might be associated with SLE susceptibility, despite the absence of a mutation resulting in amino acid alteration in the encoded protein.

We further analyzed the genotype frequencies of these BMP6 SNPs by sex between healthy controls and SLE patients, because SLE occurs more frequently in females. We found that the associations described were also true when study subjects were confined to the female population (Table 3). These results supported that these BMP6 SNPs might strongly influence SLE susceptibility, and that these effects might be sex-specific. It will be of interest to test this hypothesis using a large male SLE sample set in future research. However, it is difficult to enroll male SLE patients, given the rare occurrence of SLE in males.

The ESR and CRP levels reflect the degree of inflammation in the body. There has been debate regarding the accuracy and sensitivity of the ESR and CRP levels in various conditions, such as those associated with SLE. ${ }^{26,27}$ However, ANA levels allow detection of autoantibodies in blood serum, with ANA titers useful in the diagnosis of several autoimmune disorders, including SLE.
Moreover, monitoring ANA levels aids in predicting disease progression. ${ }^{28,29}$ In the present study, we investigated associations between BMP6 SNPs and the ESR, as well as CRP and ANA levels, as measured by analysis of variance; however, found no relevant associations (Table 4), signifying that the BMP6 SNPs did not affect the ESR, CRP, or ANA levels in SLE patients.

To examine any possible correlations between the haplotypes associated with rs1107495, rs9505273, rs17557, and rs1044104 polymorphisms and SLE susceptibility, we analyzed the haplotype frequencies of the SNPs in SLE patients and controls (Table 5). The distribution of the main haplotypes (ACCC, ATCC, GCGT, and GCCT) in BMP6 SNPs in SLE patients differed significantly from their distribution in controls (Table 5). These results put forward that these haplotypes might represent useful genetic markers for SLE. It will be of interest to validate this finding using a larger SLE sample set in future research.

The limitation of this association study was that although our results indicated that BMP6 polymorphisms might be correlated with SLE susceptibility, SLE pathogenesis cannot be explained by an association study.

In conclusion, our results suggest that BMP6 might be a candidate gene associated with SLE pathogenesis. Our results also provide a valuable resource for further functional studies of the BMP6 gene and its relationship with other autoimmune or inflammatory disorders.

\section{Declaration of conflicting interests}

The authors declared no conflicts of interest with respect to the authorship and/or publication of this article.

\section{Funding}

The genomic DNA used for this study was provided by the Biobank of Wonkwang University Hospital, a member of the National Biobank of Korea, which is supported by the Ministry of Health and Welfare. This research was supported by Wonkwang University in 2016.

\section{REFERENCES}

1. Kotzin BL. Systemic lupus erythematosus Cell 1996;85:303-6. 
2. Lisnevskaia L, Murphy G, Isenberg D. Systemic lupus erythematosus. Lancet 2014;384:1878-88.

3. Kurien BT, Scofield RH. Autoantibody determination in the diagnosis of systemic lupus erythematosus. Scand J Immunol 2006;64:227-35.

4. Yamada R, Ymamoto K. Recent findings on genes associated with inflammatory disease. Mutat Res 2005;573:136-51.

5. Hochberg MC. Updating the American College of Rheumatology revised criteria for the classification of systemic lupus erythematosus. Arthritis Rheum 1997;40:1725.

6. Guo J, Wu G. The signaling and functions of heterodimeric bone morphogenetic proteins. Cytokine Growth Factor Rev 2012;23:61-7.

7. Perrimon N, Pitsouli C, Shilo BZ. Signaling mechanisms controlling cell fate and embryonic patterning. Cold Spring Harb Perspect Biol 2012;4:005975.

8. Alarmo EL, Kallioniemi A. Bone morphogenetic proteins in breast cancer: dual role in tumourigenesis? Endocr Relat Cancer 2010;17:123-39.

9. Lories RJ, Derese I, Ceuppens JL, Luyten FP. Bone morphogenetic proteins 2 and 6, expressed in arthritic synovium, are regulated by proinflammatory cytokines and differentially modulate fibroblast-like synoviocyte apoptosis. Arthritis Rheum 2003;48:2807-18.

10. Kim HS, Jin EH, Mo JS, Shim H, Lee SS, Chae SC. The Association of the GABRP Polymorphisms with Systemic Lupus Erythematosus. J Immunol Res 2015;2015:602154.

11. Mo JS, Chae SC. EPSTI1 polymorphisms are associated with systemic lupus erythematosus. Genes Genom 2017;39:445-51.

12. Chae SC, Yu JI, Oh GJ, Choi CS, Choi SC, Yang YS, et al. Identification of single nucleotide polymorphisms in the TNFRSF17 gene and their association with gastrointestinal disorders. Mol Cells 2010;29:21-8.

13. Tan EM. Antinuclear antibodies: diagnostic markers for autoimmune diseases and probes for cell biology. Adv Immunol 1989;44:93-151.

14. Grumet FC, Coukell A, Bodmer JG, Bodmer WF, McDevitt HO. Histocompatibility (HL-A) antigens associated with systemic lupus erythematosus. A possible genetic predisposition to disease. N Engl J Med 1971;285:193-6.

15. Gateva V, Sandling JK, Hom G, Taylor KE, Chung $\mathrm{SA}$, Sun $\mathrm{X}$, et al. A large-scale replication study identifies TNIP1, PRDM1, JAZF1, UHRF1BP1 and IL10 as risk loci for systemic lupus erythematosus. Nat Genet 2009;41:1228-33.

16. Taylor KE, Remmers EF, Lee AT, Ortmann WA, Plenge RM, Tian C, et al. Specificity of the STAT4 genetic association for severe disease manifestations of systemic lupus erythematosus. PLoS Genet 2008;4:1000084.

17. Sheng YJ, Gao JP, Tang HY, Tang XF, Sun LD,
Yin XY, et al. A single-nucleotide polymorphism rs4639966 in 11q23.3 is associated with clinical features of systemic lupus erythematosus in the Chinese population. Lupus 2012;21:1538-42.

18. He CF, Liu YS, Cheng YL, Gao JP, Pan TM, Han JW, et al. TNIP1, SLC15A4, ETS1, RasGRP3 and IKZF1 are associated with clinical features of systemic lupus erythematosus in a Chinese Han population. Lupus. 2010;19:1181-6.

19. Kawasaki A, Furukawa H, Kondo Y, Ito S, Hayashi T, Kusaoi M, et al. Association of PHRF1-IRF7 region polymorphism with clinical manifestations of systemic lupus erythematosus in a Japanese population. Lupus 2012;21:890-5.

20. Li CS, Zhang Q, Lim MK, Sheen DH, Shim SC, Kim JY, et al. Association of FOXJ1 polymorphisms with systemic lupus erythematosus and rheumatoid arthritis in Korean population. Exp Mol Med 2007;39:805-11.

21. Jin EH, Shim SC, Kim HG, Chae SC, Chung HT. Polymorphisms of COTL1 gene identified by proteomic approach and their association with autoimmune disorders. Exp Mol Med 2009;41:354-61.

22. Yu JI, Chun SW, Yun KJ, Moon HB, Chae SC. TSLPR gene polymorphism is associated with systemic lupus erythematosus in the Korean population. Genes Genom 2012;34:77-82

23. Vukicevic S, Grgurevic L. BMP-6 and mesenchymal stem cell differentiation. Cytokine Growth Factor Rev 2009;20:441-8.

24. Duan J, Wainwright MS, Comeron JM, Saitou N, Sanders AR, Gelernter J, et al. Synonymous mutations in the human dopamine receptor D2 (DRD2) affect mRNA stability and synthesis of the receptor. Hum Mol Genet 2003;12:205-16.

25. Shabalina SA, Ogurtsov AY, Spiridonov NA. A periodic pattern of mRNA secondary structure created by the genetic code. Nucleic Acids Res 2006;34:2428-37.

26. Vilá LM, Alarcón GS, McGwin G Jr, Bastian HM, Fessler BJ, Reveille JD. Systemic lupus erythematosus in a multiethnic cohort (LUMINA): XXIX. Elevation of erythrocyte sedimentation rate is associated with disease activity and damage accrual. $\mathrm{J}$ Rheumatol 2005;32:2150-5.

27. Pepys MB, Hirschfield GM, Tennent GA, Gallimore JR, Kahan MC, Bellotti V, et al. Targeting C-reactive protein for the treatment of cardiovascular disease. Nature 2006 ;440:1217-21.

28. Kavanaugh A, Tomar R, Reveille J, Solomon DH, Homburger HA. Guidelines for clinical use of the antinuclear antibody test and tests for specific autoantibodies to nuclear antigens. American College of Pathologists. Arch Pathol Lab Med 2000;124:71-81.

29. Kushner I, Rzewnicki D, Samols D. What does minor elevation of C-reactive protein signify? Am J Med 2006;119:166. 